\title{
PLASTIC DEFORMATION OF METALS
}

D URING July 15-16 a conference was held at the H. H. Wills Physical Laboratory of the University of Bristol on the plastic deformation of metals, with special reference to creep and fatigue. The conference was preceded during July 13-14 by a course of lectures by members of the staff of the Laboratory on recent developments in the theory of dislocations, especially on those which are relevant to the subject-matter of the conference. The course also included a review of the experimental evidence for the existence of dislocations. At the conference the following papers were given: D. McLean (National Physical Laboratory), a survey of recent work on creep; G. Masing (Göttingen), a survey of recent work in Gottingen on the deformation of metals; A. H. Cottrell (Birmingham), effect of twisting on the tensile strength of aluminium crystals; G. B. Greenough (Sheffield), residual strains in plastically deformed iron; J. Sawkill (Sheffield), deformation of gold crystals in pure shear; J. Nutting and G. Thomas (Cambridge), plastic deformation in two-phase alloys, and metallography of duplex slip; R. Cahn (Birmingham), some results on creep in zinc; A. G. Duce and G. C. Smith (Cambridge), surface markings in fatigue; J. W. Martin (Cambridge), fatigue of internally oxidized materials; A. K. Head (Melbourne and Bristol), the rate of spread of the fatigue crack ; J. Clayton-Cave (British Iron and Steel Research Association, Sheffield), scatter of fatigue life; A. Deruyttere (Sheffield), cleavage fracture of zine single crystals; C. E. Phillips (Mechanical Engineering Research Laboratory), a discussion of the size effect in fatigue; P. J. E. Forsyth (Royal Aircraft Establishment), a discussion of the work on fatigue at the Royal Aircraft Fstablishment, Farnborough.

After listening to the papers presented at this conference, it seemed to the present writer that, though we are beginning to understand the mechanism of plastic flow and work-hardening, the same cannot be said either of creep or of the various types of fracture. The discussion after McLean's able survey of creep showed that there was no agreement as to the rate-determining process. Both slip along the brain boundaries and deformation of the grains occur, and in principle either could control the rate. Those who maintained that it is the deformation of the grains with the accompanying cell formation or polygonization that matters had to explain how the grain size could affect creep-rate. One suggestion put forward was that, when the grain size is small, slip lines will frequently terminate on the grain boundaries, and that the annealing of the strains set up there would occur more rapidly, because of the ease of self-diffusion along the grain boundary.

Prof. Masing reported on the work of the Göttingen school on 'easy glide' of metal single crystals, on its dependence on orientation and on the surface markings which result. One fact which came out very clearly from his lecture was that, under conditions of easy glide in which slip on one system only occurs, deformation bands are formed. Deformation bands, with their accompanying X-ray asterisms, are therefore not directly related to work-hardening. Although the kinematics of their formation remains obscure, it is clear that they form a configuration of low energy in which dislocations can arrange themselves, and that dislocations trapped in this way are wasted so far as hardening is concerned. It seems that, in easy glide, dislocations either escape from the crystal or form deformation bands.

Turning now to fracture, there was considerable discussion of the work at the University of Sheffield on fracture of hexagonal metals, both single crystals and polycrystals. It was generally agreed that preexisting Griffiths cracks are not the cause of fracture, but it was suggested that slip lines formed in the early stages of flow may act in a similar way. The stress around the end of a slip line is expected to be similar to that around the end of a crack, and thus to fall off with distance $r$ from the end as $\sigma \sqrt{ }(l / r)$, $\sigma$ being the applied stress and $l$ the length of the slip line. Just as, when the stress rises above a certain value, a Griffiths crack will extend, so, when the stress rises above a value of order $G \sqrt{ } /(b / l)$, we expect a crack to be initiated and to spread from the end of a slip line; $b$ is here the interatomic distance. The linear relationship found at Sheffield between fracture stress and the reciprocal of the square root of the grain size suggests an explanation of this sort; if the stress exceeds a certain value, the first slip line formed crossing a grain breaks the specimen.

On the subject of fatigue, recent work at Melbourne, at the National Physical Laboratory, at Cambridge, and at Bristol on relatively pure non-ferrous metals revealed some measure of agreement as to what is observed. During the first thousand cycles or so the metal hardens and the area of the hysteresis loop greatly contracts, and towards the end of this process some slip lines appear. This occurs both with

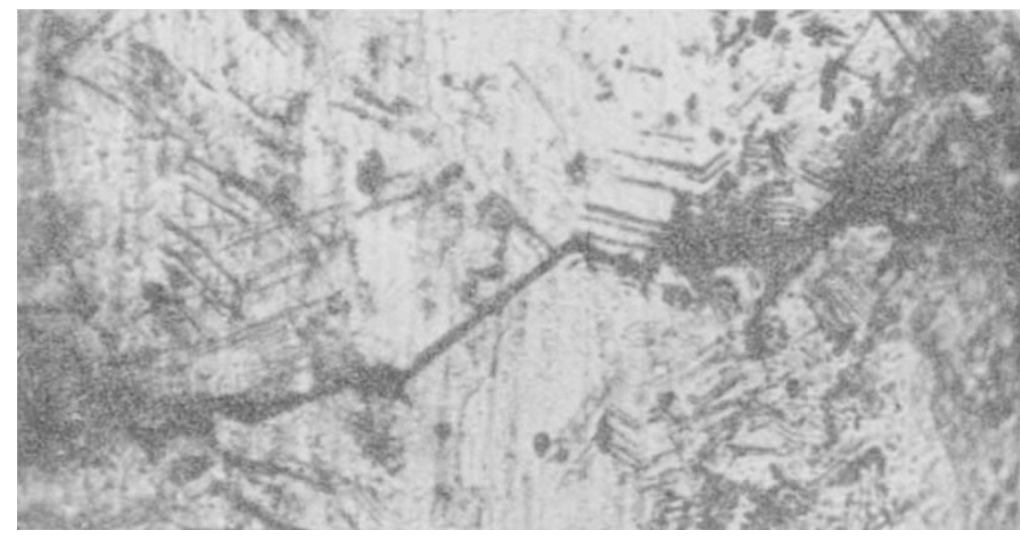

A fatigue crack in copper obtained with a high-speed fatigue machine (Thompson and wadsworth). $\times 280$ 
the very slow machine developed at Bristol, taking several minutes for each cycle, and at frequencies of $1,000 \mathrm{c} . / \mathrm{s}$. Thereafter some of the slip lines broaden, according to Duce (Cambridge) these being those oriented in the direction of maximum shear stress. This goes on throughout the second stage of fatigue, which includes the bulk of the fatigue life. As regards the hysteresis loop, at Cambridge and at Melbourne it is found that its area remained constant during the second stage, whereas Thompson (Bristol) and the investigators at the National Physical Laboratory, working at different frequencies on the same copper, found a steady increase in the energy loss, together with the appearance of new slip lines. No obvious reason for the discrepancy was suggested. Also Thompson put forward results, confirming earlier work by Sinclair and Dolan ${ }^{1}$, that frequent annealing does not increase the fatigue life of his copper specimens.

Head $^{2}$ (Melbourne) put forward a theory of the spread of a fatigue crack, obtained with many simplifying assumptions, but showing how, due to the work-hardening and subsequent fracture of the material just at the head of a crack, the slow growth of the crack might occur. He obtained the equation for the rate $\mathrm{d} c / \mathrm{d} n$ per cycle at which the length $c$ of the crack increases:

$$
\frac{\mathrm{d} c}{\mathrm{~d} n}=A c^{3 / 2}
$$

$A$ is a constant which varies rapidly with stress and otherwise depends on such quantities as the rate of strain-hardening and the limit of ductility. He gave evidence to show that his equation is in reasonable agreement with experiment, at any rate for steels.

In view of the fact that damage which cannot be destroyed by annealing occurs early on, Head suggested that almost the whole fatigue life might be associated with the spread of a crack, and that equation (1) would account quantitatively for observed fatigue-lives if the crack were said to start from a length of $10^{-4} \mathrm{~cm}$. On the other hand, Thompson showed some photographs of fatigue cracks in copper which suggest that initiation and spread of the crack are two separate processes. One of the photographs is shown in the illustration. It suggests that initiation involves the fracture of a single grain, in this case $10^{-2} \mathrm{~cm}$. in width, and only after that does a crack spread by a mechanism as conceived by Head. As observed by several authors, cracks form in the heavily worked region of the broad slip lines. This, and the fact that early damage survives annealing, would suggest that the visible crack across a grain may result from a large number of small cracks which occur as the results of stress concentration at the ends of the slip lines in a single cluster.

No account can be given here of the various surface markings and cell structures which were discussed by contributor's to the conference. Clearly the deformation of metals under alternating stress has many similarities to normal cold-work. An outstanding problem still remains, however, and that is why, over a significant range of stress, it takes as many as several million cycles to produce the effects observed. 'Sinclair G. M., and Dolan, T. J., Proc. Nat. Congress Appl. Mech.,

${ }^{2}$ Head, A. K., Phil. Mag. (in the press).

\section{BIOCHEMISTRY OF LIPIDS}

$A$ THREE-DAY colloquium on the "Biochemical Problems of Lipids", sponsored by the Royal Flemish Academy of Sciences, was held recently in Brussels under the presidency of Prof. R. Ruyssen, of Ghent. The meeting was formally opened by Prof. E. Polinard, president of the Academy. The scientific programme was divided into three main sessionsthe first dealing with the chemistry and physics of lipids and technical methods; the second being concerned with the intestinal absorption of lipids; the third with lipid biosynthesis.

The opening speaker of the first session was $\mathrm{H}$. A. Boekenoogen (Unilever Research Laboratories, $\mathrm{Z}$ wijndrecht), who reviewed the chemical character. isties and classification of the more important lipids. Some discussion arose on the use of the term 'lipid' ; it was generally felt that the wide biochemical use of the word should be retained and that the more specific chemical names available for individual lipids should be used when precise particularization is needed. The methods of dispersion of lipids in an aqueous medium and some of the factors concerned were discussed on the basis of papers in this field presented by D. Dervichian (Institut Pasteur, Paris) and P. Ekwall (Åbo). The separation of fatty acids by chromatography provoked discussion on a number of technical points following a paper on this subject by J. Boldingh (Unilever Research Laboratories, Zwijndrecht). C. Hocking (Cambridge), in a paper with J. H. Schulman (Cambridge), presented evidence of a model system that promoted the passage of negatively charged lipid particles through membranes.

Detailed consideration of molecular structure was provided by the discussion on the contributions of E. Klenk (Cologne), who described the investigation of the structure of long-chain polyethenoid fatty acids, and J. N. Hawthorne (Birmingham), who gave an account of the work he had undertaken to establish the structure of inositol-containing phosphatides derived from the soya bean. The association between lipids and proteins in biological structure was opened up by J. B. Finean (Birmingham), who gave a paper on his X-ray diffraction studies on nerve myelin. By studying the effect of drying, tension and the action of solvents, he was able to present useful data on the ultra-structure of myelin in both peripheral and optic nerve. The importance of lipids in cell structure was the subject of further debate in connexion with the membrane of the red blood cell, the stability of which formed the basis of two papers-one by R. Ruyssen (Ghent) and the other by B. A. Pethica (Birmingham).

Discussions during the second day on the intestinal absorption of lipids can be conveniently considered in relation to the three phases of absorption-intraluminar, cellular and distributive. Consideration of the intraluminar phase of absorption was opened by W. F. R. Pover (Birmingham), who described experiments on lipolysis, fine emulsification and the distribution of lipids between the oil and water phase. He presented evidence to show that both in vitro and in vivo the hydrolysis of long-chain triglycerides is likely to be incomplete, that the glyceride residue would be finely dispersed to a particle size of less than $0.5 \mu$ and that the long-chain fatty acids would be retained almost entirely in the oil phase, provided that the conditions approximated to those normally found in the upper small intestine. In contrast, 